\title{
Analysis of active system operation optimization in office buildings
}

\section{Pollack Periodica An International Journal for Engineering and Information Sciences}

16 (2021) 2, 130-135

DOI:

10.1556/606.2020.00209

(c) 2020 The Author(s)

\author{
Mohammad Reza Ganjali Bonjar ${ }^{1}$, Bálint Baranyai ${ }^{2}$, \\ Kristóf Roland Horváth ${ }^{1}$ and István Kistelegdi ${ }^{2 *}{ }^{2}$
}

\footnotetext{
${ }^{1}$ Marcel Breuer Doctoral School, Department of Building Constructions and Energy Design, Institute of Architecture, Faculty of Engineering and Information Technology, University of Pécs, Boszorkány út 2, Hungary

${ }^{2}$ Department of Building Constructions and Energy Design, Institute of Architecture, Faculty of Engineering and Information Technology, Boszorkány út 2, and Energia Design Building Technology Research Group, Szentágothai Research Center, Ifjúság útja 20, University of Pécs, H-7624 Pécs, Hungary
}

Received: February 25, 2020 • Revised manuscript received: May 21, 2020 • Accepted: September 14, 2020 Published online: April 26, 2021

\section{ORIGINAL RESEARCH PAPER}

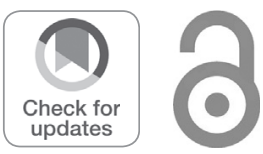

* Corresponding author.

\begin{abstract}
The aim of this paper is to present a solution for optimizing the operation of the Szentágothai Research Center. This building has several different functions at a high degree, so it can represent most of the difficulties in achieving an ideal level of operation energy consumption while assuring an adequate comfort level.

As a first stage of a generic office building optimization research, a monitored reference building of common type was chosen. Various active operation optimization experiments were carried out. The successive reduction of operation intensity and schedules resulted in $63.3 \%$ operation energy savings. The results provide considerable potential in generic office design applications.
\end{abstract}

\section{KEYWORDS}

office, lab, services systems, energy-optimization, simulation, measurements

\section{INTRODUCTION}

Office buildings, including laboratories represent the second most common building type after the residential sector [1]. In terms of sustainability, the characteristic problem of these buildings occurs in high energy demand due to the specific use (occupants, lighting, and equipment generate high internal heat loads). Further, the typical high Wall-Window-Ratio (WWR) enables high solar heat loads in summer and high heat losses in winter. A typical and still unsolved problem exists in practice, considering the operation management in this building sector. Although many publications deliver solutions for smart building automation systems, the problem remains [2]. Usually, the complete building services and electricity systems are maintained by pure automation algorithms, i.e., on-off switch is made by facility management personnel or constant (0-24 o'clock) use of Heating, Ventilation and Air Conditioning (HVAC) systems [3]. Despite of the fact current modern office facilities are equipped with several kinds of Building Management Systems (BMSs) utilizing advanced applicable operation algorithms; these facilities are not utilized or even not programmed at the level of their full potential [4].

The subject of this study is the demonstration of potential and limits in office building operation optimization, using only the existing systems and BMS. A bottom-up, step-by-step investigation intends to set the theoretical calculation domain in relation with an implemented office and laboratory building example that serves as a monitored test-bed for optimal operation search. A sensitivity analysis was utilized to identify the scenario with the 
most energy savings while appropriate comfort level is still achieved. This study shows the energy saving potential of the reference building. This was a complex task due to the several additional functions (laboratories, laboratories for in vivo testing, auditorium, atrium, dressing room, etc.) located in different building blocks, almost completely separated and supplied by different service systems. The example: Szentágothai Research Center (SRC), University of Pécs, is one of the most complex and large scaled office and research facility in Hungary, built in 2012. It generates a significant part of the operation and maintenance cost of the university. The reference building represents one of the most common office building type, regarding net floor space, number of levels, used structures, materials and renewables using HVAC systems [5], therefore the conclusions are well applicable in a more generic and broad office building design optimization.

In a first step, the reference building's energy and comfort model is created using the exact geometries and structures with default services system components, matching at best with the real buildings' systems. The model's energy and comfort performance is set in relation with the operation energy cost invoices and in situ measurements to explore the degree of the deviations. The operation optimization potential of the existing building services systems is evaluated via thermal and lighting simulations, using a base model reflecting the actual building and its systems. Optimization scenarios are carried out by applying concepts with help of the existing BMS and some more advanced automation possibilities.

\section{THE REFERENCE BUILDING}

The SRC reference building (Fig. 1) possesses $7351.8 \mathrm{~m}^{2}$ net floor spaces, comprising of 4 different building parts. The buildings' function, structures, HVAC systems and climate concept are described in former studies $[6,7]$. The 5 storey "Cube A" contains the main entrance hall, offices and seminary rooms; "Cube B" has 5 storey of regular labs and 2 large auditorium, while "Cube C" serves as a security lab unit. "Building K" includes the entrance hall and the largest auditorium, maximum 300 person can hear here lectures, conferences. The load bearing structure consists of a reinforced concrete skeleton with a $6 \times 6 \mathrm{~m}$ pillar raster and slabs. The entrance façade is a climate façade with 2 layer of glazing, while the remaining faces include $63.5 \mathrm{~cm}$ air gap between the aluminum sheet coverage and the insulated wall. This air gap integrates most part of the mechanical ventilation duct system. The slabs are constructed applying double-floors and suspended ceilings with $1 \mathrm{~m}$ air gap for the integration of the HVAC system's room units and ducts.

The structures thermal properties are the level of the minimum national energy requirement [8]. The building envelope contains $20 \mathrm{~cm}$ reinforced concrete, $16 \mathrm{~cm}$ mineral wool insulation, $63.5 \mathrm{~cm}$ ventilated air gap in the double skin climate façade and aluminum coating resulting in a $U$ value of $0.2235 \mathrm{~W} / \mathrm{m}^{2} \mathrm{~K}$. The floor slabs were constructed as $15 \mathrm{~cm}$

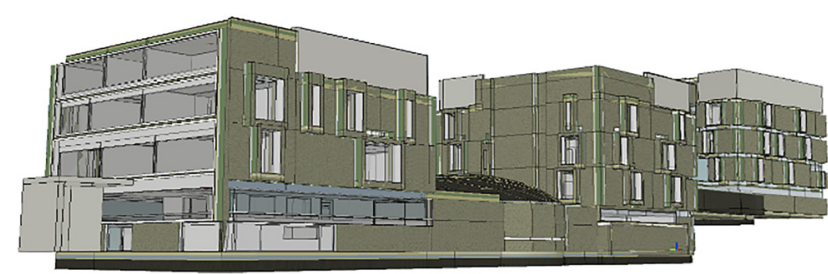

Fig. 1. 3D climate, comfort, and energy simulation model of the Szentágothai Research Center reference building (software: IDA ICE 4.8)

Extruded Polystyrene Insulation (XPS) insulation, $14 \mathrm{~cm}$ concrete flooring with a $U$ value of 0.4161 . The roof slabs were realized with suspended gypsum ceiling, $40 \mathrm{~cm}$ air gap, $30 \mathrm{~cm}$ reinforced concrete and on top $15 \mathrm{~cm}$ gravel giving a $0.0497 \mathrm{~W} / \mathrm{m}^{2} \mathrm{~K} \mathrm{U}$ value. Windows facing southwest, northwest and northeast had a $6 \mathrm{~mm}$ glass pane outside, $16 \mathrm{~mm}$ air gap and $3.3 \mathrm{~mm}$ inner glass pane with a total $\mathrm{U}$ value of 1.4, and a Solar Heat Gain Coefficient (SHGC) of 0.31/0.29/ 0.52 . The climate façade facing to the southeast contains 4 $\mathrm{mm}$ clear glass, $64 \mathrm{~cm}$ ventilated air gap, $4 \mathrm{~mm}$ solar glass, $15 \mathrm{~mm}$ air gap and $4 \mathrm{~mm}$ clear glass with a total $U$ value of 1.55 in case of closed air gap and an SHGC of 0.36/0.23/0.57.

In Table 1 the services systems has arranged. In "Cube A, B" and "Building K" 120 earth probes and water-water heat pumps deliver space heating and cooling in combination of water-air heat pumps as room units. Base heat demand is covered by the central heat pumps with Thermal Activated Suspended Ceilings (TASCs) and Near Surface Concrete Core Activated (NSCCA) ceilings. If the TASC and NSCCA power is not sufficient, the Room unit Heat Pumps (RHPs) switches on to support. In "Cube C" - as a comparison reference with the remaining part of the building - district heat and a fluid chiller is responsible for central heating and cooling with the NSCCA and fan-coil room units. Due to laboratory security reasons, Air $\mathrm{CHange}(\mathrm{ACH})$ is covered completely by mechanical ventilation, although in some part of the facility (offices, educational rooms) natural ventilation would be also possible (not open-able windows are integrated into the facades). "Building $\mathrm{K}$ " represents the Auditorium and "Cube B" provides the heating and cooling power to the coils in "Building K's" Air Handling Unit (AHU), thus "Building K" has no separate heating, cooling system. In Table 1 Energy Efficiency Ratio (EER) and Coefficient Of Performance (COP) are presented.

\section{SIMULATION MODEL CALIBRATION}

The building is modeled in the thermal and lighting simulation software environment IDA ICE 4.8 (Fig. 1) using the Meteonorm climate database [9]. Rooms and their corresponding window openings with same orientation and functions were merged together in the model resulting in a total of 164 climate zones. The heating-cooling room units, which belong to a zone or a zone-group, were merged as well. This simplifications enabled not only saving 
Table 1. HVAC Building services systems' properties in "Cube A, B" and "Building K"

\begin{tabular}{|c|c|c|c|c|}
\hline Systems & Building & Description & Capacity kW & Efficiency \\
\hline \multirow[t]{5}{*}{ Heating-cooling center } & "Cube A" + entrance hall & $\begin{array}{l}\text { Water-water heat pumps with } 143 \times \\
100 \mathrm{~m} \text { earth probe system }\end{array}$ & $\begin{array}{l}\text { Heating: } 197 \\
\text { Cooling: } 193\end{array}$ & $\begin{array}{l}\text { COP } 4.28 \\
\text { EER } 4.28\end{array}$ \\
\hline & "Cube B" + "Building K" & Water-water heat pumps with $143 \times$ & Heating: 339 & COP 4.28 \\
\hline & AHU & $100 \mathrm{~m}$ earth probe system & Cooling: 333 & EER 4.28 \\
\hline & "Cube C" & District heating & Heating: 371 & COP 0.82 \\
\hline & & Fluid chiller & Cooling: 468 & EER 4.05 \\
\hline \multirow{5}{*}{$\begin{array}{l}\text { Room units heating- } \\
\text { cooling }\end{array}$} & "Cube A" & TASC/RHP & Zone & COP 3.94 \\
\hline & & & dependent & EER 3.37 \\
\hline & "Cube B" & NSCCA/RHP/fan coil & Zone & COP 3.94 \\
\hline & & & dependent & EER 3.37 \\
\hline & "Cube C" & NSCCA/fan coil & $\begin{array}{c}\text { Zone } \\
\text { dependent }\end{array}$ & \\
\hline Systems & Building & Description & Capacity & Air flow \\
\hline \multirow[t]{4}{*}{ Air Handling Unit (AHU) } & "Cube A" + entrance hall & Heat recovery $81 \% / 0.79 \mathrm{ACH}$ & $\begin{array}{l}\text { Heating: } 64 \\
\text { Cooling: } 48\end{array}$ & $13.645 \mathrm{~m}^{3} / \mathrm{h}$ \\
\hline & "Cube B" & Heat recovery $79 \% / 5.02 \mathrm{ACH}$ & $\mathrm{H}: 100 / \mathrm{C}: 96$ & $29.605 \mathrm{~m}^{3} / \mathrm{h}$ \\
\hline & "Cube C" & Heat recovery $78 \% / 4.46 \mathrm{ACH}$ & $\mathrm{H}: 144 / \mathrm{C}: 100$ & $34.600 \mathrm{~m}^{3} / \mathrm{h}$ \\
\hline & "Building K" & Heat recovery $80 \% / 4.37 \mathrm{ACH}$ & $\mathrm{H}: 164 / \mathrm{C}: 102$ & $\begin{array}{l}\text { HVAC "Cube } \\
\text { B" }\end{array}$ \\
\hline
\end{tabular}

considerable calculation time but it was anyway necessary for successful simulation runs, since complexity and size of the project exceeds the capability of even the most developed simulation programs.

The different degree of modeling simplifications has been estimated due to available information and complexity of the building and its HVAC systems. The geometry, room arrangement, structures and materials as well as the envelope and WWR were modeled exactly as in reality. The model of the central plant, the mechanical ventilation and the ceiling tempering system comply with the reference building's systems. The double plant services system architecture contains 2 groups of systems to provide heating and cooling: the central heat pumps (primary system) serves the base demand of the room units, as the ceiling radiation system and the RHP-s, while these RHP-s serve as a secondary system as well to satisfy peak loads. In case of Cube $\mathrm{A}$ and $\mathrm{B}, \mathrm{RHPs}$ heating EER was $7.4 \%$ less effective than the modeled RHP, and the modeled heat pump systems COP showed $23.1 \%$ less effectiveness compared to the final plans. During modeling the hydraulic systems simplifications where required due to simulation software limitations. The complicated hydraulic connection between the primary and secondary systems, further the complex integration of the RHP-s into the mechanical ventilation system is a simulation task at prototypical difficulty level, requiring extra research.

Room unit air-conditioners and heat pumps substitute the RHP-s, since these room units possess the greatest similarity in system specifications. Model applies merged earth probes, heat pumps, as well as simplified hydraulic connections between earth probes, heat pump, hot and cold tanks and pumps.

The lack on field survey of occupancy, schedule and METabolic rate (MET), lighting and equipment during real use brought a further uncertainty factor. As a first step, to handle this problem, American Society of Heating, Refrigerating and Air-Conditioning Engineers ASHRAE code [10, 11] based schedules and internal gains were chosen as it is listed in Table 2. In this way, the model can be regarded as a first stage of achieved calculus accuracy level that is able to deliver appropriate estimations.

The final energy performance was measured by a BMS, monitoring district heat and electricity consumption, as well as HVAC system operation set-points, states and indoor air temperature parameter with 109 room temperature measurement points.

The monitored electricity consumption of the systems is approximate yearly total values. Comparison was carried out between the two years of average measurement (2017 and 2018) and the according simulation case of Operation Scenario (OS) 0 and 1. After an iteration simulation process, the consistency between measurement and calculation results amounted approx. 76-95\% in the different building parts and in the various HVAC systems, as it is shown in Fig. 2.

Main reason for the deviation is the previously described modeling simplification (Table 3) in the HVAC systems' hydraulic system and the missing exact schedule assessment of the lighting equipment, as well as occupancy. Since the mean inaccuracy level in the system consumption values is $12.95 \%$, whereby the maximum deviation is only 2-times exceeding the $20 \%$ threshold (21.62 and $23.97 \%$ ), the comparison can be acknowledged as an estimated model calibration. Model accuracy means that in each "Cube" the ratio of measured and calculated (simulated) consumption of heating, cooling and HVAC aux was calculated an averaged. For "end-validation" purposes, in next stage of research, detailed collection, and modeling of the internal use parameters as well as the in-depth HVAC hydraulic system model-development should adjust the last incompatibilities. 
Table 2. Typical internal gains-boundary conditions

\begin{tabular}{|c|c|c|c|c|c|c|}
\hline & \multicolumn{3}{|c|}{ Measured } & \multicolumn{3}{|c|}{ Simulation } \\
\hline & Use & Properties & Schedule & Pcs. & MET & Schedule \\
\hline \multirow[t]{4}{*}{ Occupancy } & Office & Final plan & Real use & 5 & MET:1 & 08-18 weekdays \\
\hline & Laboratory & Final plan & Real use & 7 & MET:1 & $5 \times 90$ min weekdays_75\% \\
\hline & Auditorium & Final plan & Real use & 99 & MET:1 & $5 \times 90$ min weekdays_75\% \\
\hline & Corridor & Final plan & Real use & 1 & MET:1 & 6-18 5 min_hour \\
\hline \multirow[t]{4}{*}{ Lighting } & Office & Final plan & Real use & 7 & $100 \mathrm{~W}$ & 08-18 weekdays \\
\hline & Laboratory & Final plan & Real use & 5 & $150 \mathrm{~W}$ & 08-18 weekdays \\
\hline & Auditorium & Final plan & Real use & 20 & $150 \mathrm{~W}$ & $5 \times 90$ min weekdays_75\% \\
\hline & Corridor & Final plan & Real use & 3 & $150 \mathrm{~W}$ & 6-18 5 min_hour \\
\hline \multirow[t]{3}{*}{ Equipment } & Office & Final plan & Real use & 5 & $375 \mathrm{~W}$ & 08-18 weekdays \\
\hline & Laboratory & Final plan & Real use & 11 & $375 \mathrm{~W}$ & $5 \times 90$ min weekdays_75\% \\
\hline & Auditorium & Final plan & Real use & 14 & $376 \mathrm{~W}$ & $5 \times 90$ min, weekdays_75\% \\
\hline
\end{tabular}

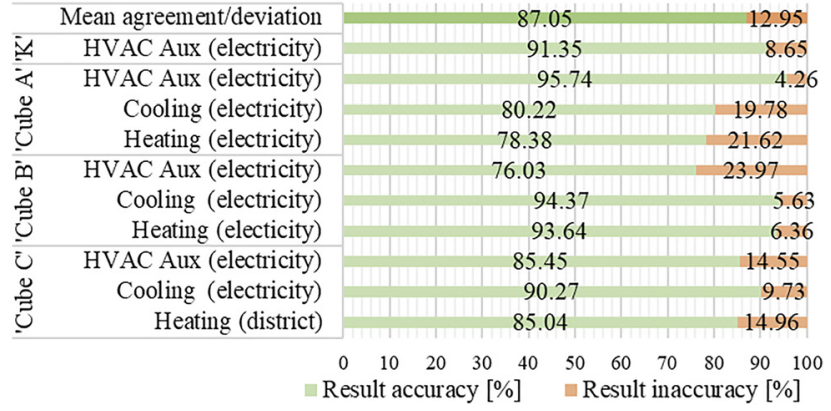

Fig. 2. Calculated and measured yearly energy performance results in the reference building

\section{ACTIVE SYSTEM OPERATION OPTIMIZATION}

\subsection{Operation scenarios}

Considering the existing HVAC system, the most effective measure to reduce energy consumption in the building was reducing the AHU performance levels. In the laboratories changing the AHU performance was very limited due to the constant occupancy or certain experiments. Other factors had also shaped the bounds of the operation strategies i.e., changing any setting as operation experiment had to be submitted to the corresponding authorities of the university.
During finalizing the operation scenarios, one of the key factors was the gradual reduction of the service systems operation schedules. The various ventilator settings were developed in accordance with the facility management of the building.

The operation scenarios (Table 3) intend to increase energy efficiency by reducing operation intensities and time schedules or employing control strategies.

Operation scenario OS 0 : The active systems were operated in the first approx. 5 years with full load, 24 hours per day, meaning the mechanical ventilation system, the central heating-cooling system, as well as the room units run at highest level of operation stage. This was considered as the reference case - operation scenario 0 . At the same time, this performance discovers the maximum energy consumption of the building. OS 1, the first optimization of the operation decreases the ventilator running intensity in a degree that is still able to maintain appropriate $\mathrm{ACH}$ in the various sections of the facility. Based on real occupancy schedules, OS 2 concept reduces the AHU operation of OS 1 by offsetting the system during night and weekend. OS 3 is a developed version of OS 2, by switching off the central heat pump, fluid chiller and district heat exchanger as well as the heat pumps and fan coils in the rooms. This is the most realistic operation strategy due occupancy schedules. OS 4 proposes the modification of OS 3 with $\mathrm{CO}_{2}$-control of the AHU system.

Table 3. Active system operation scenarios as optimization concepts

\begin{tabular}{|c|c|c|c|c|c|c|c|}
\hline $\begin{array}{l}\text { Operation } \\
\text { Scenario }\end{array}$ & $\begin{array}{l}\text { HVAC } \\
\text { System }\end{array}$ & $\begin{array}{l}\text { AHU-A1/ } \\
\text { AHU-A2 }\end{array}$ & $\begin{array}{l}\text { AHU-B1/ } \\
\text { AHU-B2 }\end{array}$ & $\begin{array}{c}\text { AHU-C1/AHU-C2/ } \\
\text { AHU-C3 }\end{array}$ & AHU-K & $\begin{array}{l}\text { Central heating- } \\
\text { cooling system }\end{array}$ & $\begin{array}{l}\text { Room unit } \\
\text { system }\end{array}$ \\
\hline OS 0 & $\begin{array}{l}\text { Operation } \\
\text { Schedule }\end{array}$ & $\begin{array}{c}100 \% \\
0-24 \mathrm{~h}, \text { daily }\end{array}$ & $\begin{array}{c}100 \% \\
0-24 \mathrm{~h}, \text { daily }\end{array}$ & $\begin{array}{c}100 \% \\
0-24 \text { h, daily }\end{array}$ & $\begin{array}{c}100 \% \\
0-24 \mathrm{~h}, \\
\text { daily }\end{array}$ & $\begin{array}{c}100 \% \\
0-24 \mathrm{~h} \text {, daily }\end{array}$ & $\begin{array}{c}100 \% \\
0-24 \mathrm{~h} \text {, daily }\end{array}$ \\
\hline OS 1 & $\begin{array}{l}\text { Operation } \\
\text { Schedule }\end{array}$ & $80 \% / 80 \%$ & \multicolumn{3}{|c|}{ Same as OS 0} & \multicolumn{2}{|c|}{ Same as OS 0} \\
\hline OS 3 & $\begin{array}{l}\text { Operation } \\
\text { Schedule }\end{array}$ & \multicolumn{6}{|c|}{ Same as OS 1} \\
\hline OS 4 & $\begin{array}{l}\text { Operation } \\
\text { Schedule }\end{array}$ & & Same as & $\mathrm{S} 1+\mathrm{CO}_{2}$ & OS 0 & \multicolumn{2}{|c|}{$\begin{array}{c}5-23 \mathrm{~h} \text {, workdays } \\
\text { Same as OS } 0\end{array}$} \\
\hline
\end{tabular}


According to the operation scenarios, in OS $0-3$ the regular AHU equipment ensures the required $\mathrm{ACH}$ with scheduled supply air temperature control. In "Building K", the supply air temperature control is complemented by an exhaust air temperature regulation via Proportional Integral (PI) control and return air $\mathrm{CO}_{2}$-concentration is controlled with a smoothed proportional PI controller, combined with a mixing-box economizer that recirculates indoor air if its $\mathrm{CO}_{2}$-concentration allows this. If the return air $\mathrm{CO}_{2}$-concentration approaches $700 \mathrm{ppm}$, the P-controller permits gradually $100 \%$ outdoor air supply, and in case of lower return air $\mathrm{CO}_{2}$-concentration, the recirculation of exhaust air decreases the amount of outdoor air ratio in supply air. In $\mathrm{OS} 4, \mathrm{CO}_{2}$-concentration based piecewise proportional controllers are installed in the regular AHU machines of "Cube $\mathrm{A}, \mathrm{B}$, and C". The $\mathrm{CO}_{2}$-control regulates fan operation in time and intensity due to the $\mathrm{CO}_{2}$-level of 750-900 ppm as a sophisticated "occupancy control" mechanism.

\section{RESULTS AND DISCUSSION}

The thermal model served as initial basis for model modifications in the HVAC system according to the concepts of OS 1 to OS 5. The simulation and monitoring time interval added up to 1 year.

For the thermal comfort evaluation, the number of occupancy hours assessed, which perform a Predicted Mean Vote (PMV) belonging to thermal comfort class II (normal expectations, recommended for new and renovated buildings according to EN 15251). Compared to OS 0 the deviation interval stays in the range of $0.27-13.8 \%$, that is acceptable and comparable when considering that 73.9$97.36 \%$ of the complete yearly operation (including nights and weekend with decreased system operation) PMV class II is provided. OS 4 performs unacceptable overheating with $14.56 \%$ decreasing deviation compared to OS 0 in class II PMV hours (operative temperatures between 28 and $30{ }^{\circ} \mathrm{C}$ almost every day of the year) - therefore this case became inconsiderable.

Figure 3 assesses the purchased final energy results of heating, cooling, ventilation, and pump consumption in the operation scenarios. In the evaluation of the energy results HVAC aux means fan and pump electricity consumption. The reference case (OS 0) possesses obviously the highest demand, while the optimization cases gradually reduce the energy expenses.

In "Cube A and C" similar improvement tendency is obtained due to characteristically analog operation settings. HVAC aux and heating demand is improved 31.9 and $13.5 \%$ ("Cube A") and 52.5 and $41.7 \%$ ("Cube C") in OS 1. In "Cube C" this case performs the highest degree of savings by setting $\mathrm{AHU}$ ventilator stage most intensively to a lower level that still maintain appropriate $\mathrm{ACH}$. The night and weekend switch-off in the ventilation system (OS 2) decreases further $47.4 \%$ HVAC aux and $27.9 \%$ heating ("Cube $A$ ") and 35 and 40.1\% ("Cube C") energy conservation, while the same switch-off potential applied in the central
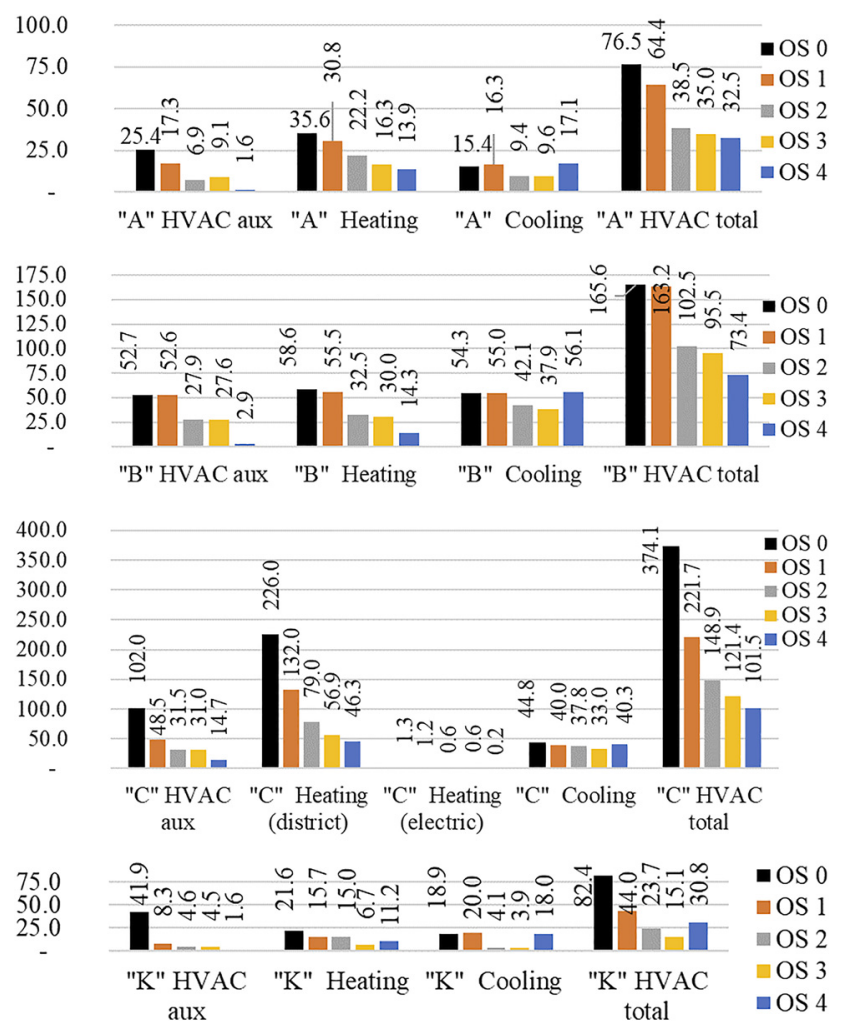

Fig. 3. Final energy consumption $\left[\mathrm{kWh} / \mathrm{m}^{2} \mathrm{a}\right]$ performance of the HVAC operation optimization concepts; from top to bottom: "Cube A", "Cube B", "Cube C", "Building K"

plant (OS 3) provides further 26.6 and $28 \%$ heating saving in "Cube A and C". In "Cube A" OS 2 saved the largest degree of energy by decreasing AHU's operation time. The purchased cooling energy is significantly lower than the heating, since there is a decisive efficiency deviation between heat pump Heating Seasonal Performance Factor (HSPF) 3.6 and Cooling Seasonal Performance Factor (CSPF) 6.58 with the earth probe system, further between district heating (COP 0.82) and fluid chiller (EER 4.05). Successively, cooling conservation in "Cube C" is improved by $10.7 \%$ in OS 1 , further $5.6 \%$ in OS 2 and another $12.5 \%$ in OS 3. In "Cube A" only OS 2, the night, and weekend switch-off in the ventilation system delivers significant reduction (43.3\%).

In "Cube B" there is no difference between OS 0 and OS 1 , because of no settings difference was undertaken. Due to specific lab requirements in this building part, the facility management could not allow any AHU intensity reduction. OS 2 reduced $47 \%$ HVAC auxiliary power, $41.4 \%$ heating and $23.4 \%$ cooling demand of the AHU system, while OS 3 only marginally improved the operation expenses. In this building section, only the plant operation time was reduced, resulting in smaller savings. This is also the reason, why the cooling demand is at comparably level as of the heating.

In "Building K" only the AHU system is installed and heating and cooling demand of the AHU coils are supplied by "Cube B" plant. In this section, the entrance hall ventilation and heating-cooling supply is covered by the plant and AHU system of "Cube A". The reduction of the AHU 
operation stage by $76 \%$ delivered $98.5 \%$ ventilation savings. The AHU operation time reduction produced further $37.7 \%$ conservation, meaning the optimum operation case.

The optimization affect in "Cube A, B, and C" most intensively the heating and HVAC aux demand, since in the cooling season solar gains worked contra-productively during the weekend switch-off periods, generating peak loads on Mondays. OS 3, the intensity and schedule reduction of the mechanical ventilation and the schedule reduction of the plant can be considered as the most efficient operation optimization strategy for all building parts within the boundary conditions of the existing HVAC systems. Compared to the initial OS 0 , OS 3 improved the total energy demand in "Cube A" by $59.2 \%$ (64.1\% HVAC aux, 54.2\% heating and 37.6\% cooling savings) and in "Cube B" by $42.3 \%$ (47.6\% HVAC aux, $48.8 \%$ heating and $30.2 \%$ cooling reduction) and in "Cube C" by $67.5 \%$ (69.6\% ventilation, 74.8 heating and $26.3 \%$ cooling conservation).

\section{CONCLUSION}

A monitored generic modern office and lab building was proven to be used as a reference test-bed for office building optimization. In case of lack on use-profiles and high hydraulic system complexity, the application of norm based model simplifications can appropriately substitute the missing level of detail in a thermal and lighting simulation model. Results serve as a good estimation for future high resolution model calibration. The achieved level of model accuracy $(87.05 \%)$ is feasibly sufficient to serve the assessment of optimization potential difference percentages. A series of optimization concepts modified the operation in the existing HVAC system. Though the $\mathrm{CO}_{2}$ controlled OS 4 demonstrates the best improvement in energy efficiency, the overheating in the solely mechanically ventilated building shows the limits of the absence of natural ventilation. The successive reduction of operation intensity and schedule duration reached $63.3 \%$ electricity operation energy savings (OS 3), representing the considerable potential of carefully handled building operation management in a broad scale of generic office buildings and large scaled public facilities. A next step will further detail the HVAC hydraulic system in the model and integrate a survey database about the buildings real lighting, equipment and occupancy profiles in order to create an end-validated model.

\section{REFERENCES}

[1] M. Jradi, C. T. Veje, and B. N. Jørgensen, “A dynamic energy performance-driven approach for assessment of buildings energy renovation - Danish case studies", Energ. Build., vol. 158, pp. 6276, 2018.

[2] S. Tang, D. R. Shelden, C. M. Eastman, P. Pishdad-Bozorgi, and X. Gao, "BIM assisted building automation system information exchange using BACnet and IFC", Automation Construct., vol. 110, Paper no. 103049, 2020.

[3] C. Srivastava, Z. Yang, and R. K. Jain, "Understanding the adoption and usage of data analytics and simulation among building energy management professionals: A nationwide survey", Build. Environ., vol. 157, pp. 139-164, 2019.

[4] H. B. Gunay, M. Ouf, G. Newsham, and W. O’Brien, "Sensitivity analysis and optimization of building operations", Energ. Build., vol. 199, pp. 164-175, 2019.

[5] J. Verhelst, G. Van Ham, D. Saelens, and L. Helsen, "Model selection for continuous commissioning of HVAC-systems in office buildings: A review”, Renew. Sustain. Energ. Rev., vol. 76, pp. 673686, 2017.

[6] B. Póth and I. Kistelegdi, "Energy and climate simulations and management system in the Szentágothai Research Center”, Pollack Periodica, vol. 9, no. 1, pp. 61-70, 2014.

[7] B. Póth and I. Kistelegdi, "The history of the energy and climate concept of the Szentágothai Research Center", Pollack Periodica, vol. 8, no. 3, pp. 3-14, 2013.

[8] Minister without Portfolio Decree No. 7/2006. (V. 24.) TNM on the establishment of energy characteristics of buildings. [Online]. Available: http://njt.hu/cgi_bin/njt_doc.cgi? docid=101820. 298385. Accessed: Feb. 25, 2020.

[9] Meteonorm 7. [Online]. Available: https://meteonorm.com/en/. Accessed: May 21, 2020.

[10] 2013 ASHRAE Handbook. Fundamentals, Chapter 9: Thermal comfort. [Online]. Available: https://qut.rl.talis.com/items/ 190573CD-DE5C-1443-F08A-FD09E36CECF9.html. Accessed: Feb. 25, 2020.

[11] M. J. Brandemuehl, S. Gabel, and I. Andresen, HVAC 2 Toolkit: A Toolkit for Secondary HVAC System Energy Calculations, Refrigerating and Air Conditioning Engineers, TC 4.7 Energy Calculations. Atlanta, Ga, American Society of Heating, Refrigerating and Air-Conditioning Engineers, 1993. 